\title{
How to Avoid the Pseudo Environment of Users' Knowledge Contribution?-Taking the Online Question and Answer Platform as an Example
}

\author{
Xiuyu Liu \\ Shandong University of Technology, Zibo, China \\ Email:2280583144@qq.com
}

How to cite this paper: Liu, X. Y. (2022). How to Avoid the Pseudo Environment of Users' Knowledge Contribution?-Taking the Online Question and Answer Platform as an Example. Voice of the Publisher, 8 , $10-15$.

https://doi.org/10.4236/vp.2022.81002

Received: December 14, 2021

Accepted: February 27, 2022

Published: March 2, 2022

Copyright $\odot 2022$ by author(s) and Scientific Research Publishing Inc. This work is licensed under the Creative Commons Attribution International License (CC BY 4.0).

http://creativecommons.org/licenses/by/4.0/

\begin{abstract}
Information dissemination is based on human will, and it is purposeful and artificial. There is a certain subjectivity in the knowledge contribution of users of online question-and-answer platform, which builds a pseudo environment.
\end{abstract}

\section{Keywords}

Knowledge Contribution, Pseudo Environment, Impact, Measures

\section{Introduction}

The territory of knowledge is boundless, and its content is complex and diverse. Some people are the senders and some people are the receivers of knowledge. From the perspective of communication, the knowledge contribution of online users is the sender of knowledge. Definition of knowledge contribution: users share and output information, technology and their own ideology in the absence of knowledge of the receiver, and then they are absorbed, utilized and internalized by the receiver. In this process, different users' responses to online questions and answers are also based on personal values and emotions, and the output of knowledge information is often influenced by the personal environment, which is the pseudo environment in the sense of communication.

\section{The Theory of Pseudo Environment and the Practical Significance of Information Dissemination Such as Knowledge}

As for the description of pseudo-environment, in the 1920s, American journalist 
Lipman's Public Opinion mentioned: "The information environment formed by mass communication activities is not a mirror-like representation of the objective environment, but an environment that the mass media suggested to people after re-structuring the news and information" (Lippmann, 2006). In the process of knowledge dissemination, users have information asymmetry due to the differences of their own knowledge bases, the variation of information transmission and the development of knowledge will lead to the asymmetry of information and the appearance of information pseudo environment.

\section{The Analysis of the Characteristics of Pseudo Environment of Users' Knowledge Contribution}

\subsection{Have the Nature of Real Life}

In the knowledge contribution of users, the online question-and-answer platform is the distribution center for netizens to seek answers and express their opinions. Based on the anonymity of the platform, the relationship between users and audiences who contribute knowledge has been re-established, getting rid of the shackles of their respective political, economic and cultural ideologies, and their opinions have been fully expressed freely. Because of the grass-roots nature and extensiveness of users, the sources of knowledge and other information tend to be secularized, and the network pseudo environment created by knowledge information is closer to the real society.

\subsection{Infinite Knowledge and Limited Contribution Range}

Existence is perceived, but there is no boundary in the universe where we live, and our knowledge of all things in the universe is endless. The infinity of knowledge reveals that human exploration of knowledge is advancing and bumpy. Individuals have never been the "gods" who should know everything. Except for pathology, individuals are receiving information from babbling to devoting themselves to nature, and they are crawling on the road of seeking knowledge. Because of individual differences, which include the individual itself and the external environment, the knowledge contributed and received by the individual will not be the complete set. In this partial knowledge expression, the knowledge information will be in an asymmetric state.

\subsection{A Certain Degree of Stratification Guidance}

There are categories of knowledge, but long-term expectation at one level will inevitably be guided by the ideas of the knowledge at the level where it belongs. The online question-and-answer platform is generally limited knowledge in knowledge request, contribution and acceptance. No matter individuals or groups, the audience always shows differences in some aspects when receiving information, and various layers are formed in these differences. For example, in terms of age stratification, children, teenagers, youth, middle-aged and old people will show differences when they are exposed to knowledge. Children are influenced by their 
physiological and psychological development, and their understanding is not deep enough, so children are more willing to receive cartoons, nursery rhymes and easy-to-understand pictures.

\section{Network Users' Knowledge Contribution Produces Positive Pseudo Environment}

The positive pseudo environment generated by online users' knowledge is manifested in the pseudo environment of self-propagation, and the audience really broadens the accessible field of knowledge; Under the pseudo environment of interpersonal communication, the audience and knowledge contributors have a certain resonance; Under the pseudo environment of mass communication, knowledge contribution is beneficial to influence the trend of social hot events.

\section{Negative Pseudo Environment Generated by Users' Knowledge Contribution}

\subsection{Contributors Have the Potential to Create a Personal Subjective Information Cocoon}

If a person has his own opinion and understanding, and has the intention to express it, he will output information, which is fused by his own experience and environment. In view of this kind of environment that individuals use knowledge and other information to create and imprison the audience, the academia has given the definition of information cocoon. This concept was put forward by Keith Sunstein, a professor at Harvard Law School and legal adviser to President Obama in the book Information Utopia-How People Produce Knowledge published in 2006. He studied the Internet and explained that in the process of information dissemination, the information needs of the public are not comprehensive, and the public only pay attention to the things they choose and the communication fields that make them happy. Over time, they will shackle themselves (Sunstein, 2006). The "guided by your own interests" mentioned here is due to pure personal liking and the recommendation of the algorithm for taste similarity. Under this double attack, the thickness of cocoon room is thickened, which makes people unconscious and unable to escape.

\subsection{Irrational Guidance of Knowledge Superposition to the Audience}

The information aggregation reaction is to put all the information that can be gathered together in a specific environment, which can expand its utility and maximize its function and influence. This kind of aggregation reaction is the result of superposition. When the knowledge is aggregated and output, it is easy to input knowledge to the audience, while those who are not good at various aspects and deep levels are easy to be guided. For this kind of layered aggregation superposition of knowledge, most of the audience also know that these are only parts that can't replace the whole, but they are in the pseudo environment of 
public opinion of aggregation effect, and many people can't make correct judgments, but can only be guided by the superimposed knowledge information.

\subsection{Knowledge Curse and "Hammer Theory" in Mimic Environment}

When people know a lot about a certain aspect and have professional knowledge, he will pass it on in various ways, perhaps expressing his meaning by words or actions, but others don't know what he said and did, and he thinks he has made it clear, so at this time, he is "cursed" by his professional knowledge. This is a negative effect on knowledge contributors indulging in their own pseudo environment, and also makes them even try the "hammer theory", that is, when a person knows that he is holding a hammer in his hand, he will see everything like a nail (Maslow, 2007). This theory has a certain solidification effect on the thinking method of solving problems, consolidating the knowledge barriers of knowledge contributors, thickening the wall of professional knowledge curse, and making it difficult for yourself to open up the knowledge territory. In such a pseudo environment, the audience will follow the footsteps of knowledge contributors and come to the city-state of knowledge pseudo environment.

\section{How to Break the Pseudo Environment in Knowledge Contribution}

\subsection{Rational Self-Cognition}

In the final analysis, the pseudo environment created intentionally or unintentionally by knowledge dissemination contributors is the sender of information, and it is the person who really handles knowledge or receives it. After the users' knowledge contribution, the first is to stand firm and define their thinking goals. In the pseudo environment, the output of users' emotional ideas may be more or less in conflict with the values of the audience. When the influence of contributors is above the subjectivity of the audience, the audience will easily be led by the nose and will be completely integrated into the pseudo environment over time. Second, after acquiring knowledge, in the process of processing and internalizing knowledge, objectively and rationally analyze the source, position, interest attribution, expression principle methodology and influence of knowledge.

\subsection{Jump out of the Fixed Layer, and Don't Let Solidification Challenge Your Thinking of Dealing with Knowledge}

Because of the different layers in which individuals are different, each layer has its own cultural characteristics, and it will also have edification and subtle influence on the individuals in which they are located. Long-term thinking is solidified like layers of yellow sand flying all over the northwest. After a period of hovering, the dust finally settles, so layers of coverage can't find where to go home. How to raise the yellow sand and jump out of the hazy illusion of Loulan needs 
to be done in the process of knowledge processing: first, think from multiple angles, exercise your own thinking, and form an all-round and three-dimensional thinking mode. Second, try to think backwards and exercise reverse thinking. The commonness of these two points is that we should be active in thinking, and we can't be one-sided. Everything is not isolated, and the connection is universal. Mining knowledge and information can't solidify our thinking because of one-sidedness. With this unique defensive ability, individuals will not be affected by the pseudo environment of knowledge contributors.

\subsection{Contributors of Knowledge Break the Curse of Knowledge and Build the Integration System of Disciplines}

First, knowledge contributors need to break the curse of knowledge. They should not only be self-centered, but also integrate the essence that can be extracted in various disciplines to achieve the effect that can be understood by the audience. Second, after the audience receives knowledge by themselves, the processing needs to build a multidisciplinary integration system. Breaking the knowledge curse is not the responsibility of the knowledge contributors, but the audience should also participate in other aspects of knowledge outside their own disciplines. How to escape the curse of knowledge, ability is both an advantage and a trap. First of all, you should not preset roles and change positions at any time. Secondly, in order for the audience to understand what they have stated, it is necessary for us to be prepared to repeat it countless times. Psychologist Jerome Bruner: If a message is repeated 20 times, it is likely to be remembered accurately. Finally, when encountering complicated problems, learn to speak flexibly and communicate in parts. When your goal changes, so should your story (Party, 2019). Charlotte Biers, the former CEO of Ogilvy \& Mather Group, once instructed Maria, a manager, to regard herself as a "person who is very concerned about things around her".

\subsection{Be Good at Giving up and Tapping Tacit Knowledge from a New Direction}

Knowledge can be divided into explicit knowledge and tacit knowledge. Explicit knowledge is most easily accepted by the audience, while tacit knowledge often hides itself by its obscurity. Explicit knowledge is "conspicuous" but not "important". People always need to form a certain knowledge system in the process of mastering a certain skill, and explicit knowledge is just the tip of the iceberg. Below the iceberg is abundant tacit knowledge. "Implicit knowledge is more basic than explicit knowledge: people can know more than people can tell." (Xiao, 1999). Because of this, Polanyi reminds people to pay attention to "tacit knowledge" and "personal knowledge" that have been suppressed and neglected for a long time (Qian, 2005). Mining tacit knowledge means externalizing tacit knowledge into explicit knowledge, and then internalizing it into your own knowledge. There are three ways for individuals to make tacit knowledge explicit: process recall, situation simulation and introspection. The process of recall is the 
process of trying to recall some unknown so's intuition. With the help of the richness of background information, it activates the relevant information of the similar nodes in the memory network, so that the vague intuition impression rises to the level of consciousness and becomes explicit. The operation method of the simulation is the same as the process recall. Their key is to let the individual return to the original environment when the event happened or artificially create a scene when the simulation event happened, and activate the recall by using the memory traces that once made him familiar with the situation, and then make the intuitive impression related to the event easily rise to the level of consciousness. Introspection refers to focusing attention on weak tacit knowledge and making it explicit through individual will power.

\section{Summary}

Human's understanding and exploration of the world is the source of knowledge, the network is the distribution center of knowledge in modern times, and the online question and answer platform is the porter of knowledge. Especially in this era of knowledge and information flooding, whether the receiver of knowledge is alienated by the pseudo environment created by knowledge contributors in view and thinking is something that the audience should pay attention to. From the perspective of social psychology of communication, this paper analyzes the pseudo environment on the online question-and-answer platform. Because of existence, there is no end to the pursuit of knowledge, and the pursuit of knowledge will never stop. The transmitter unintentionally, the receiver intentionally and objectively contributes knowledge and rationally receives knowledge.

\section{Conflicts of Interest}

The author declares no conflicts of interest regarding the publication of this paper.

\section{References}

Lippmann, W. (2006). Public Opinion. Shanghai: Shanghai People’s Publishing House.

Maslow (2007). Theory of Human Motivation. Xu, J. S. et al. (Trans.). Beijing: Renmin University of China Press.

Party, J. F. (2019). People in Middle Age Should Know How to Live and Earn a Living. China Aviation News.

Qian, Z. H. (2005). Science: Humanity, Belief and Value-Research on Polanyi's Humanistic Science View. Shanghai: Fudan University.

Sunstein, K. (2006). Information Utopia-How People Produce Knowledge. Law Press China.

Xiao, G. L. (1999). Tacit Knowledge, Tacit Understanding and Scientific Research. Research on Dialectics of Nature, 8 . 